\title{
Binding to PCNA in Euryarchaeal DNA Replication Requires Two PIP Motifs for DNA Polymerase D and One PIP Motif for DNA Polymerase B
}

\author{
Benoît Castrec $^{1,2}$, Christophe Rouillon ${ }^{1,2}$, Ghislaine Henneke ${ }^{1,2}$, Didier Flament ${ }^{1,2}$, Joël \\ Querellou ${ }^{1,2}$ and Jean-Paul Raffin 1, 2, 3, *
}

\footnotetext{
${ }^{1}$ Université de Bretagne Occidentale, UMR 6197, Laboratoire de Microbiologie des Environnements Extrêmes, BP 70, F-29280 Plouzané, France

2 IFREMER, UMR 6197, Laboratoire de Microbiologie des Environnements Extrêmes, BP 70, F-29280 Plouzané, France

${ }^{3}$ CNRS, UMR 6197, Laboratoire de Microbiologie des Environnements Extrêmes, BP 70, F-29280 Plouzané, France

Present address: C. Rouillon, Biomedical Sciences Research Complex, North Haugh, University of St. Andrews, St. Andrews, Fife Scotland, KY16 9ST, UK.
}

*: Corresponding author : Jean-Paul Raffin, Tel.: +33 2982245 39; Fax: +33 29822 47 57, email address : ipraffin@ifremer.fr

\begin{abstract}
:
Replicative DNA polymerases possess a canonical C-terminal proliferating cell nuclear antigen (PCNA)-binding motif termed the PCNA-interacting protein (PIP) box. We investigated the role of the PIP box on the functional interactions of the two DNA polymerases, PabPol B (family B) and PabPol D (family D), from the hyperthermophilic euryarchaeon Pyrococcus abyssi, with its cognate PCNA. The PIP box was essential for interactions of PabPol B with PCNA, as shown by surface plasmon resonance and primer extension studies. In contrast, binding of PabPol D to PCNA was affected only partially by removing the PIP motif. We identified a second palindromic PIP box motif at the Nterminus of the large subunit of $P a b P o l D$ that was required for the interactions of $P a b P o l D$ with PCNA. Thus, two PIP motifs were needed for PabPol D for binding to PabPCNA. Moreover, the Cterminus of PabPCNA was essential for stimulation of PabPol D activity but not for stimulation of $P a b P o l$ B activity. Neither DNA polymerase interacted with the PabPCNA interdomain connecting loop. Our data suggest that distinct processes are involved in PabPol D and PabPol B binding to PCNA, raising the possibility that Archaea require two mechanisms for recruiting replicative DNA polymerases at the replication fork.
\end{abstract}

Keywords: DNA replication; DNA polymerases; PCNA-binding motifs; PIP box; Archaea

Abbreviations: IDCL, interdomain connector loop of PCNA; Pab, Pyrococcus abyssi; PCNA, proliferating cell nuclear antigen; PabPCNA, Pyrococcus abyssi PCNA; PabPol B, Pyrococcus abyssi family B DNA polymerase; PabPol D, Pyrococcus abyssi family D DNA polymerase; PabPol B $\Delta$ pip and PabPol D $\Delta$ pip, DNA polymerases lacking the C-terminal PIP box motif; PabPol DNcut, PabPol D lacking the N-terminus of the large subunit; PIP, PCNA-interacting protein; Pfu, Pyrococcus furiosus; $\mathrm{RF}-\mathrm{C}$, replication factor C; SPR, surface plasmon resonance. 


\section{INTRODUCTION}

DNA replication is a functionally conserved mechanism among all organisms including Bacteria, Eukarya, Archaea and viruses ${ }^{1,2}$ that ensures genome stability. ${ }^{3}$ The process takes place through a variation of a theme with a protein triad composed of a DNA polymerase holoenzyme with two accessory factors, the sliding clamp and the clamp-loader. In E. coli, the chromosomal replicase is a DNA polymerase III complex encompassing the two protein factors in addition to the polymerizing core subunits. ${ }^{45}$ Recently, O’Donnell and his coworkers suggested that three Pol III complexes could assemble to form a triple replisome. ${ }^{6}$ In eukaryotes, two replicases, belonging to family B, ensure faithful copying of the entire genome. DNA polymerase $\delta$ is composed of three ${ }^{7}$ to four ${ }^{8,9}$ essential subunits, while DNA polymerase $\varepsilon$ is active as a heterotetramer. ${ }^{10}$ Recent genetic studies on DNA polymerases $\delta$ and $\varepsilon$ strongly suggest that they are essential for DNA replication. DNA polymerase $\delta$ might be responsible for Okazaki fragments synthesis on the lagging strand while DNA polymerase $\varepsilon$ is likely to perform leading strand synthesis. ${ }^{11,12}$

A fascinating relationship has been found between the eukaryal and archaeal DNA replication proteins. Indeed, informational proteins in Archaea are more closely related to their eukaryotic rather than their bacterial counterparts. Moreover, the functional interaction between the eukaryotic DNA polymerase $\delta$ and the archaeal accessory factors, PCNA and RFC was conserved through evolution. ${ }^{13,14}$

Yet, the archaeal replication factors from thermococcales display unique functional properties. Indeed, while ATP hydrolysis is required for clamp-loading in Eukaryotes, ${ }^{15}$ in Archaea, the RF-C complex could load the PCNA without the need for ATP hydrolysis. ${ }^{16}$ Also, the PCNA stimulated the B and D family DNA polymerases on a circular DNA template in the absence of the RF-C. ${ }^{17}$ Moreover, the spontaneous loading of the PCNA from 
Pyrococcus abyssi, hereafter named PabPCNA, can be enhanced not only by RF-C but also by Pol B. ${ }^{18}$

Within the archaeal domain, it has been established that significant divergence can be found within the main sub-domains, i.e. Euryarchaea and Crenarchaea. Indeed, up to three PCNA homologues were found in Crenarchaea ${ }^{19,20}$ which were incriminated to form a heterotrimer in vivo, ${ }^{21}$ while a single PCNA homologue that forms a homotrimer was found in Euryarchaea. These assemblies demonstrate how protein components have evolved distinctly in Archaea. Moreover, the spectrum of cellular DNA polymerases is highly divergent within these subdomains. Crenarchaea possess mainly up to three family B monomeric DNA polymerases, ${ }^{22,23}$ while Euryarchaea possess one monomeric family B DNA polymerase and one heterodimeric family D DNA polymerase supposed to be restricted to this sub-domain. ${ }^{24-26}$ However, Pol D was also detected in the genome of Candidatus Korarchaeum cryptofilum, ${ }^{27}$ Nanoarchaeum equitans $^{28}$ and Cenarchaeum symbiosum. ${ }^{29}$

Generally, replicative DNA polymerases need to be chaperoned by the sliding clamp to become rapid and processive. ${ }^{30}$ Interactions of proteins with the sliding clamp are mediated through common motifs, like the PCNA Interacting Protein (PIP) box. ${ }^{31}$ It can be defined as $\operatorname{Qxx}(\mathrm{h}) \operatorname{xx}(\mathrm{a})(\mathrm{a})$, where “ $\mathrm{x}$ ” is any amino acid, " $\mathrm{h}$ ” is a hydrophobic residue (I, L or M), and “a” is a aromatic residues (F, Y or W). A large number of replication and repair proteins, including error prone DNA polymerases have the consensus PIP motif. ${ }^{32,33}$ Recent studies have demonstrated that the PIP box is not always sufficient to account for interactions with PCNA. This seems to indicate that a region proximal to the core-conserved domain makes a significant contribution to PCNA interaction. ${ }^{34}$ Moreover, a helix-hairpin-helix (HhH) motif, important for proper DNA primer binding of DNA polymerase $\lambda$, was shown to physically interact with PCNA. ${ }^{33}$ In addition, a C-terminal region of DNA polymerase $\lambda$, which is not related to the PIP box, was described and suggested that specific PCNA-binding motifs could 
be related in a negative regulation of the nucleotidyl transferase activity. ${ }^{35}$ Looking over a random peptide library, a new polymorphic PCNA-binding motif (KA-box) was recently identified in human Pol $\delta$ and also in other proteins like members of MCM family, mismatch repair protein MSH6 or cyclin D3. ${ }^{36}$ Finally, the binding of DNA polymerase $\delta$ to PCNA was shown to be mediated by a glycine-rich region (GX4GX8GX3YFY).$^{37}$ However, PCNAinteracting peptides play a role not only through their sequences but also at a structural level. Indeed, recent studies have shown that PCNA binding of PCNA-interacting peptides is independent of the specific sequence. ${ }^{38}$ Moreover, the PIP-peptides are mediated through beta zipper formation at the interaction surface. ${ }^{39}$ Usually, the PIP-box motifs interact preferentially with the hydrophobic pocket ${ }^{40,41}$ of PCNA, defined by the C-terminus and the interdomain connecting loop (IDCL). Therefore, the PCNA interacting partners, and especially DNA polymerases, bind the clamp through a complex set of motifs that have no match with the PIP box. In accord with this idea, we searched for unraveled PCNA binding motifs within archaeal DNA polymerases in order to decipher the physical assembly of functional DNA Pols and PCNA in Archaea. 


\section{RESULTS}

\section{Functional and physical interactions between PabPCNA and PabPol B but not PabPol D are mediated by the C-terminal PIP box motif.}

The C-terminal PIP box of PabPol B and PabPol D was deleted (Fig. 1a). For PabPol B, physical interactions with the PabPCNA were abolished, indicating the importance of this structural motif for PCNA binding (Fig. 1b). On the contrary, deletion of the putative PIP box of the PabPol D only moderately impaired the binding to PabPCNA (Fig. 1b), suggesting that other critical residues may interact with PabPCNA.

The functional interactions of PabPol B with PabPCNA were also abolished when the PIP box was removed (Fig. 2, lanes 7-10). Indeed, the addition of PabPCNA led to full-length M13 DNA synthesis by PabPol B (Fig. 2, lanes 7 and 8), whereas, the lengths of products synthesized by PabPol B $\Delta$ pip were not modified by adding PabPCNA (Fig. 2, lanes 9 and 10). On the contrary, removing the putative PIP box of the large subunit of PabPol D had no effect on the stimulation of the DNA polymerase activity by the PabPCNA (Fig. 2, lanes 3-6). Quantitative analysis of the data in Fig. 2, performed on six independent experiments, also showed no significant difference in PCNA stimulation for wild-type and $\triangle$ pip PabPol D. Then, primer elongation activities of PabPol B and PabPol D have been tested in the presence of PabPCNA and competitor peptides, PIPB and PIPD, the primary structures of which correspond to the respective PIP-boxes (Fig. 3). While adding the control peptide TEMD had no significant effect on primer elongation by PabPol B (Fig. 3a, lanes 4-5), the PIPB peptide clearly inhibited the stimulation of the sliding clamp for long fragments synthesis (Fig. 3a, lanes 6-7). This is a confirmation that the functional interaction of PabPol B is PIP boxdependent. Interestingly, the PIPD peptide suppressed the interaction between Pol B and PCNA signifying that the PIP box of PabPol D is functionally comparable to the PIP box of 
PabPol B (Fig. 3a lanes 8-9). Furthermore, PIPD and PIPB peptides also entered in competition with PabPol D, as observed by the absence of full-length M13 fragments (Fig. 3b, lanes 3-4). This observation was reinforced by the lack of PCNA stimulation of PabPol D $\Delta$ pip in presence of PIPD and PIPB peptides (Fig. 3c lanes 4 and 5), suggesting the need for an additional critical PCNA-binding motif within PabPol D.

\section{A novel N-terminal motif in PabPol D is required for functional interactions with PabPCNA to occur.}

Since the C-terminal PIP box motif of PabPol D had no essential role in the interactions with PabPCNA, we looked for other putative PCNA-binding motifs in DNA polymerase D. A novel motif localized at the N-terminus was identified. This putative PIP box (10YEEMLQREIDKAY-22) could correspond to a palindromic motif schematized by the following sequence: $(\mathrm{a}) \mathrm{xx}(\mathrm{h}) \mathrm{x}(\mathrm{Q}) \mathrm{xx}(\mathrm{h}) \mathrm{xxx}(\mathrm{a})$, where glutamine 15 is located in the middle of the sequence (Fig. 4a).

Functional interactions of PabPol D deleted at the N-terminus (PabPol DNcut) with PabPCNA were strongly inhibited, although not abolished (Fig. 4b). Quantitative analysis of the data in Fig. 4b, performed on three independent experiments, showed that PCNA stimulation was significantly reduced in PabPol DNcut as compared to PabPol D. Besides, primer elongation activities of PabPol D have been tested in the presence of PabPCNA and the competitor peptides Nter 1 and Nter 2 (Fig. 5). These peptides correspond to the primary structures of the sequence upstream and downstream of glutamine 15, respectively. Stimulation of PabPol D was still observed in the presence of peptides Nter 1 and Nter 2, which were added separately with peptide TEMD (Fig. 5, lanes 8-15). However, stimulation of PabPol D processivity was highly reduced when both peptides were present 
(Fig. 5, lanes 18 and 19). This result confirms clearly the role of the entire palindromic PIP box sequence at the N-terminus of PabPol D for interactions with the PCNA.

\section{The C-terminus of PabPCNA is essential for PabPol D but not for PabPol B stimulation} In order to highlight the critical residues of PabPCNA involved in physical interactions with PabPols, different mutations have been introduced within conserved structural domains (Fig.

6). By using the crystal structure of PfuPCNA ${ }^{42}$ and different results on eukaryotic PCNA, ${ }^{43-45}$ a PabPCNA structure has been modelled and putative amino acids have been targeted for mutational analyses. Firstly, we generated three mutants in the IDCL region: EIE120, VDL123 and EL127. Then, proline and arginine located at the C-terminus were replaced by alanine. All these mutations are represented in Fig. 6.

Native polyacrylamide gel was used to estimate the homotrimeric organization of individual PCNA mutants which migrated as a single band at about $85 \mathrm{kDa}$ like the wild type PCNA (Data not shown).

Then, primer elongation activities of PabPol B, PabPol D and its mutants PabPol D $\Delta$ pip and PabPol DNcut were tested in the presence of the mutated PabPCNA in optimal stimulation conditions for each DNA polymerase (Fig. 7). All of PCNA mutants stimulated PabPol B (Fig. 7). PabPol D was stimulated by EIE120, VDL123 and EL127 PCNA mutants while PR245 was not able to enhance primer extension by PabPol D (Fig. 7). This result indicates that the C-terminus of PCNA is a critical factor for physical interaction with Pol D. Also, PabPol D $\triangle$ pip and PabPol DNcut were stimulated by PCNA mutants with the exception of PR245 (Fig. 7). Overall, our results demonstrated that PCNA binding of PabPol D is probably carried out via the PIP motifs location at the N- and C-terminus respectively. 


\section{DISCUSSION}

PCNA-binding motifs appear to be divergent and even the PIP box has a polymorphous nature. In the human DNA polymerase $\delta$ p66 subunit, a N-terminal region of the canonical PIP motif contributed significantly to the interactions with PCNA. ${ }^{34}$ In the Pol X family, a non-canonical PIP box belongs to a longer PCNA-binding motif with a conserved helixhairpin-helix $(\mathrm{HhH})$ domain. ${ }^{33}$ Also, PIP box-like motifs can be found in the core of most DNA polymerases. As an example, PIP box-like motifs were found in the large subunit of PfuPol D at amino acids positions $1096-1103$ and $1253-1261 .{ }^{17}$ In PabPol B, the LxxFG motif is found at positions 745-750 and two LxxFY motifs are found in the large subunit of PabPol D in the amino acids sequence 894-904. Therefore, it can be assumed that functional PIP box motifs are located at the terminal parts of the interacting proteins. In this study, we gave further insight in to the physical and functional interactions of PabPols with its cognate PCNA. While PabPol B was shown to carry only one PIP box motif at the C-terminus, PabPol D was demonstrated to contain two PIP-type motifs that interact with PCNA. Therefore, these results suggest that at the replication fork PabPol D might be loaded and stimulated differently by PCNA compared with PabPol B. Contrary to PabPol B, removing the canonical C-terminal PIP motif from PabPol D did not disrupt the physical interactions with the PCNA, although we demonstrated, by the use of competitor peptides, that this shortened motif was functionally a PIP box. Interestingly, the N-terminal PCNA-interacting motif in PabPol D is a palindromic putative PIP box defined by the sequence (10YEEMLQREIDKAY-22). We show here that this sequence is part of the surfaces interacting with the sliding clamp. Besides, both peptides corresponding to the N-terminus inhibited interactions between PabPol D and PabPCNA at higher amounts than PIPD peptide (500 $\mu \mathrm{M}$ versus $30 \mu \mathrm{M})$. Finally, while the situation is clear for PabPol B, which interacts with PCNA 
via one motif, PCNA-binding of PabPol D is carried out at least by two motifs at the $\mathrm{N}$ - and C-terminus respectively. This result does not fit in with those from recent in vitro experiments ${ }^{46}$ which show clearly that PfuPol D interacts functionally with PfuPCNA at its Cterminal PIP box. This is surprising since Pol D from Pyrococcus abyssi and Pyrococcus furiosus share strong similarities within their primary structure and particularly through their PIP box motif. Moreover, these authors demonstrated the binding of PfuPols to PfuPCNA in the absence of DNA, contrary to our previous results ${ }^{47}$ where the presence of DNA was fully required. Besides, the absence or the presence of DNA, the amount of PCNA, relative to the DNA polymerases, is also an important factor. Indeed, as shown in Fig. 4b, for the mutant Pol $\mathrm{D}$, an excess of PCNA would lead to the erroneous conclusion that the $\mathrm{N}$-terminal part is the only PCNA-interacting motif.

In the eukaryotic PCNA, three domains are known to be involved in protein-protein interactions: ${ }^{48,49}$ the interdomain connecting loop is a major interaction site and is recognized by several proteins, such as Pol $\delta$, p21, Fen1 and DNA ligase 1 ; the N-terminal region comprising the inner $\alpha$-helices forms part of the binding site for cyclin D; the C-terminal tail important for interactions with Pol $\varepsilon$ and RF-C. Since PabPol D as well as PabPol D $\Delta$ pip did not interact with the C-terminus mutant of the PCNA (see Fig. 7), and given that the interactions between PabPol D and PabPCNA are inhibited by competitor peptides mimicking the PIP boxes, we can assume that the two PIP-motifs of PabPol D interact in the same zone of the PCNA (i.e. the C-terminus). In addition, since no PCNA mutant affected the binding of PabPol B, we cannot propose any hypothesis about the region of binding of this DNA polymerase on the PCNA. More studies are required to answer these questions. This hypothesis raises the question of steric accessibility of the PCNA sites, especially when high molecular weight complexes are involved. Besides, the PIP box motif may be a flexible connector. ${ }^{50}$ In addition, PCNA interactions with more than one partner have to be considered 
as proposed for the crenarchaeal heterotrimeric clamp. ${ }^{21}$ Besides, it has been shown in the bacteriophage RB69 that the DNA polymerase, owing to a PIP box-like peptide, binds only to one site on the sliding clamp, the other two preserving the ability to bind additional proteins. ${ }^{50}$ This property would allow, through a structural reorganisation of the bound protein, accessibility to the free PCNA binding sites for another protein. Additionally, it has been shown that p21 interferes strongly with PCNA stimulation by Pol $\delta$ but does not effectively inhibit the loading of the PCNA by RF-C, ${ }^{51}$ which argues for different binding sites for Pol $\delta$ and RF-C. Furthermore, it has been proposed that RF-C travels with Pol $\delta$ and PCNA. ${ }^{52}$ Nevertheless, we cannot answer if both motifs interact in the same monomer or two different monomers. Besides, we cannot say whether two motifs of PabPol D interact on PCNA at the same time, alternatively or in a preferential order depending on replication and/or on repair partners steps. Finally, it is clear that PCNA binding occurs differently both DNA polymerases of Pyrococcus abyssi, which may imply that PCNA acts as a pivotal replication factor to coordinate and enhance DNA synthesis of the two PabPols at the leading and lagging strands, as hypothesized by previous studies. ${ }^{47}$ 


\section{MATERIALS AND METHODS}

\section{Recombinant proteins}

The Pyrococcus abyssi family B DNA polymerase (PabPol B) used was the Isis ${ }^{\mathrm{TM}}$ DNA polymerase commercialized by Qbiogene (Illkirch, France). PabPol D and PabPCNA were

prepared as described earlier. ${ }^{16,26}$ Mutant versions of both DNA polymerases with the deleted PIP box were obtained using the QuickChange ${ }^{\mathrm{TM}}$ site-directed Mutagenesis kit (Stratagene Europe, Amsterdam, The Netherlands). The codons for lysine 768 and lysine 1440 were replaced with a stop codon just upstream of the PIP box, respectively for PabPol B and PabPol D (Fig. 1a).

The construction of an expression system for the PabPol DNcut deletion mutant consisted to in deleting the N-terminal first's 22 amino acids by introduction of an NdeI recognition sequence. The gene encoding PabPol DNcut, cloned into the plasmid pET25b+ (Promega), was amplified by PCR using the oligonucleotides 5’-

CAGAGGGAGATAGATAAGGCCCATATGATAGCTAAAAAGGCGAGG-3’ and 3’GTCTCCCTCTATCTATTCCGGGTATACTATCGATTTTTCCGCTCC-5’. The NdeI recognition sequence is underlined. The gene was digested by NdeI and reintroduced in the pET25b+ plasmid. The entire nucleotide sequence was confirmed by sequencing. The gene was co transformed into E. coli HMS174 (DE3) pLysS with the plasmid pET28b+ containing the gene encoding the small subunit of PabPol D.

In the PCNA mutants, proline 245 and arginine 246 (PR245), glutamic acid 120, isoleucine 121 and glutamic acid 122 (EIE120), valine 123, aspartic acid 124 and leucine 125 (VDL123), glutamic acid 127 and leucine 128 (EL127) were replaced for by alanine (Fig. 6). The mutants were obtained using the following oligonucleotides: 5'-TGAT ATTCCTCCTGGCTGCCGCGGTTGAGGAG-3’ and 3’- 
GACTATAAGGAGGACCGACGGCGCCAACTCCTC-5’ (PR245) ; 5’-

ATAGATGTTGAGGCGGCCGCAGTTGACTTGCCAGAG-3’ and 3’-

ATCTACAACTCCGCCGGCGTCAACTGAACGGTCTC-5’' (EIE120) ; 5’-

GAGGAGATCGAAGCTGCCGCGCCAGAGTTACCC-3’ and 3’-CTC

CTCTAGCTTCGACGGCGCGGTCTCAATGGG-5’ (VDL123) ; 5’-

ATCGAAGTTGACTTGCCAGCGGCACCCTTCACG-3’ and 3’-

TAGCTTCAACTGAACGGTCGCCGT GGGAAGTGC-5’' (EL127). The PCR products were cloned into the plasmid pET25b+ (Promega) and the entire nucleotide sequence was confirmed by sequencing. All mutants have been expressed with Rapid Translation System 500 E. coli HY Kit by Roche Diagnostics (Mannheim, Germany).

The peptides used as competitor for PCNA were synthesised by Eurogentec. PIPB corresponded to the C-terminal extremity of PabPol B (765-QKTKQVFLGAWLKF-778), PIPD corresponded to the C-terminal extremity of PabPol D large subunit (1438PKKKRVISLEEFFSRKSK-1455), Nter 1 corresponded to the N-terminus of PabPol D large subunit (1- MELPKEMEEYEEMLQ-15), Nter 2 corresponded to the N-terminal domain of PabPol D large subunit (15-QREIDKAYEIAKKAR-29) and TEMD corresponded to an internal sequence of PabPol D (83-EIIEGKFGDLGSREKYAEQAV-103) and was used as control. The theoretical pI of the competitor peptides PIPB, PIPD, Nter1, Nter2 and TEMD were 10.3, 10.57, 3.98, 9.52 and 4.59, respectively.

\section{Primer extension assay}

The 32-nt oligonucleotide used to prepare the primed DNA substrate for primer extension (5'TGCCAAGCTTGCATGCCTGCAGGTCGACTCTA-3') was synthesized, labelled at the 5' terminus with 6-carboxyfluorescein, and purified by Eurogentec (Belgium). M13ssc was 
annealed to the 32-nt oligonucleotide at a 1:3 molar ratio, in $10 \mathrm{mM}$ Tris- $\mathrm{HCl} \mathrm{pH}$ 8.0, $50 \mathrm{mM}$ $\mathrm{NaCl}$, by heating at $75^{\circ} \mathrm{C}$ for $10 \mathrm{~min}$ followed by cooling to room temperature. Primer extension was performed in a final volume of $11 \mu \mathrm{l}$ containing the following components: 0.09 pmol of template/primer, 2 pmol of each dNTP, 0.02 to 1.5 pmol of PabPCNA and PabPols to be tested in the buffer (50 mM Tris-HCl pH 8.8, 1 mM dithiothreitol (DTT), $10 \mathrm{mM} \mathrm{KCl,} 2 \mathrm{mM} \mathrm{MgCl}_{2}$ ). Reactions were incubated at $60^{\circ} \mathrm{C}$ for 30 min and stopped on ice by adding $10 \mu \mathrm{l}$ of stop buffer (98 \% (v/v) formamide, 0.2 mM EDTA, pH 8.0). Peptides (30 $\mu \mathrm{M}$ to $1000 \mu \mathrm{M}$ as indicated) and PabPols were added simultaneously to start the reaction and incubations were performed at $60^{\circ} \mathrm{C}$ for $15 \mathrm{~min}$ and then stopped on ice. The products were heated at $95^{\circ} \mathrm{C}$ for $5 \mathrm{~min}$ and resolved for $16 \mathrm{~h}$ at $30 \mathrm{~V}$ at $4^{\circ} \mathrm{C}$ on a $1 \%(\mathrm{w} / \mathrm{v})$ alkaline agarose gel (50 mM NaOH, 1 mM EDTA). Finally, the products were visualized on a Typhoon 9400 imager (Amersham Biosciences).

\section{Surface plasmon resonance (SPR) experiments}

SPR analyses were performed on a BIAcore X apparatus (BIAcore, Uppsala, Sweden. DNA surfaces consisted in approximately 200 resonance units (RU) of biotinylated template immobilized onto a streptavidin surface (SA sensor chip, BIAcore) as already described. ${ }^{47}$ The interaction between PabPols and the complex DNA/PCNA were monitored as follows: PabPCNA (200 nM) was injected over the DNA chip and PabPols (200 nM) were supplemented 30 seconds after injection. In all experiments, the interactions were monitored at $25^{\circ} \mathrm{C}$ at a flow rate of $30 \mu \mathrm{l} / \mathrm{min}$ in HBS-P buffer (10 mM Hepes $\mathrm{pH} 7.4,150 \mathrm{mM} \mathrm{NaCl}$, 0.005\% (v/v) surfactant P20). 


\section{Acknowledgements}

The work was supported by a grant from the European Union (Project QLK3-CT-2002-02071

REPBIOTECH). BC and CR were supported by a grant from Région Bretagne (211-B2-

9/ARED) and Ifremer. DF also thanks ANR and Brittany regional council for financial support. We are grateful to Pascal Trouvé for giving access to the BIAcore apparatus (INSERM U.613, Génétique Moléculaire et Génétique Epidémiologique, Brest, France). 


\section{REFERENCES}

1. Kelman, Z. \& O'Donnell, M. (1994). DNA replication : enzymology and mechanisms. Curr. Opin. Genet. Develop. 4, 185-195.

2. Forterre, P., Filée, J. \& Myllykallio, H. (2004). Origin and evolution of DNA and DNA replication machineries. In The Genetic Code and the Origin of Life (de Pouplana, L. R., ed.), pp. 145-168. Kluwer Academic/Plenum Publishers, New-York.

3. Toueille, M. \& Hübscher, U. (2004). Regulation of the DNA replication fork: a way to fight genomic instability. Chromosoma, 113, 113-125.

4. O'Donnell, M., Jeruzalmi, D. \& Kuriyan, J. (2001). Clamp loader structure predicts the architecture of DNA polymerase III holoenzyme and RFC. Curr. Biol. 11, R935-R946.

5. Johnson, A. \& O'Donnell, M. (2005). Cellular DNA replicases: components and dynamics at the replication fork. Annu. Rev. Biochem. 74, 283-315.

6. McInerney, P., Johnson, A., Katz, F. \& O'Donnell, M. (2007). Characterization of a triple DNA polymerase replisome. Mol. Cell 27, 527-538.

7. Burgers, P. M. J. \& Gerik, K. J. (1998). Structure and processivity of two forms of

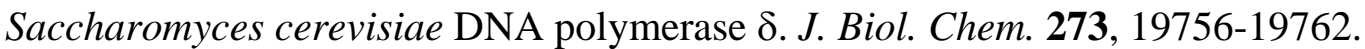

8. Zuo, S., Bermudez, V., Zhang, G., Kelman, Z. \& Hurwitz, J. (2000). Structure and activity Associated with multiple forms of Schizosaccharomyces pombe DNA polymerase $\delta$. $J$. Biol. Chem. 275, 5153-5162.

9. Podust, V. N., Chang, L.-S., Ott, R., Dianov, G. L. \& Fanning, E. (2002). Reconstitution of human DNA polymerase $\delta$ using recombinant baculoviruses. The p12 subunit potentiates DNA polemirizing activity of the four-subunit enzyme. J. Biol. Chem. 277, 3894-3901. 
10. Chilkova, O., Jonsson, B. H. \& Johansson, E. (2003). The quaternary structure of DNA polymerase epsilon from Saccharomyces cerevisiae. J. Biol. Chem. 278, 14082-14086.

11. Nick McElhinny, S. A., Gordenin, D. A., Stith, C. M., Burgers, P. M. J. \& Kunkel, T. A. (2008). Division of labor at the eukaryotic replication fork. Mol. Cell 30, 137-144.

12. Fukui, T., Yamauchi, K., Muroya, T., Akiyama, M., Maki, H., Sugino, A. \& Waga, S. (2004). Distinct roles of DNA polymerases $\delta$ and $\varepsilon$ at the replication fork in Xenopus egg extracts. Genes Cells 9, 179-191.

13. Henneke, G., Raffin, J. P., Ferrari, E., Jónsson, Z. O., Dietrich, J. \& Hübscher, U. (2000). The PCNA from Thermococcus fumicolans functionally interacts with DNA polymerase $\delta$. Biochem. Biophys. Res. Commun. 276, 600-606.

14. Ishino, Y., Tsurimoto, T., Ishino, S. \& Cann, I. K. (2001). Functional interactions of an archaeal sliding clamp with mammalian clamp loader and DNA polymerase $\delta$. Genes Cells 6, 699-706.

15. Gomes, X. V. \& Burgers, P. M. J. (2001). ATP utilization by yeast replication factor C. I. ATP-mediated interaction with DNA and with Proliferating cell nuclear antigen. J. Biol. Chem. 276, 34768-34775.

16. Henneke, G., Gueguen, Y., Flament, D., Azam, P., Querellou, J., Dietrich, J., Hübscher, U. \& Raffin, J. P. (2002). Replication Factor C from the hyperthermophilic archaeon Pyrococcus abyssi does not need ATP hydrolysis for clamp-loading and contains a functionally conserved RFC PCNA-binding domain. J. Mol. Biol. 323, 795-810.

17. Cann, I. K. O., Ishino, S., Hayashi, I., Komori, K., Toh, H., Morikawa, K. \& Ishino, Y. (1999). Functional interactions of a homolog of proliferating cell nuclear antigen with DNA polymerases in Archaea. J. Bacteriol. 181, 6591-6599. 
18. Rouillon, C., Henneke, G., Flament, D., Querellou, J. \& Raffin, J. P. (2007). DNA polymerase switching on homotrimeric PCNA at the replication fork of the euryarchaea Pyrococcus abyssi. J. Mol. Biol. 369, 343-55.

19. De Felice, M., Sensen, C. W., Charlebois, R. L., Rossi, M. \& Pisani, F. M. (1999). Two DNA polymerase sliding clamps from the thermophilic archaeon Sulfolobus solfataricus. J. Mol. Biol. 291, 47-57.

20. Daimon, K., Kawarabayasi, Y., Kikuchi, H., Sako, Y. \& Ishino, Y. (2002). Three Proliferating Cell Nuclear Antigen-like proteins found in the hyperthermophilic archaeon Aeropyrum pernix: Interactions with the two DNA polymerases. J. Bacteriol. 184, 687694.

21. Dionne, I., Nookala, R. K., Jackson, S. P., Doherty, A. J. \& Bell, S. D. (2003). A heterotrimeric PCNA in the hyperthermophilic archaeon Sulfolobus solfataricus. Mol. Cell 11, 275-282.

22. Cann, I. K. O., Ishino, S., Nomura, N., Sako, Y. \& Ishino, Y. (1999). Two family B DNA polymerases from Aeropyrum pernix, an aerobic hyperthermophilic crenarchaeote. $J$. Bacteriol. 181, 5984-5992.

23. Iwai, T., Kurosawa, N., Itoh, Y. H., Kimura, N. \& Horiuchi, T. (2000). Sequence analysis of three family B DNA polymerases from the thermoacidophilic crenarchaeon Sulfurisphaera ohwakuensis. DNA Res. 7, 243-251.

24. Cann, I. K. O., Komori, K., Toh, H., Kanai, S. \& Ishino, Y. (1998). A heterodimeric DNA polymerase: Evidence that members of Euryarchaeota possess a distinct DNA polymerase. Proc. Natl. Acad. Sci. USA 95, 14250-14255.

25. Ishino, Y., Komori, K., Cann, I. K. O. \& Koga, Y. (1998). A novel DNA polymerase family found in Archaea. J. Bacteriol. 180, 2232-2236. 
26. Gueguen, Y., Rolland, J. L., Lecompte, O., Azam, P., Le Romancer, G., Flament, D., Raffin, J. P. \& Dietrich, J. (2001). Characterization of two DNA polymerases from the hyperthermophilic euryarchaeon Pyrococcus abyssi. Eur. J. Biochem. 268, 5961-5969.

27. Elkins, J. G., Podar, M., Graham, D. E., Makarova, K. S., Wolf, Y., Randau, L., Hedlund, B. P., Brochier-Armanet, C. l., Kunin, V., Anderson, I., Lapidus, A., Goltsman, E., Barry, K., Koonin, E. V., Hugenholtz, P., Kyrpides, N., Wanner, G., Richardson, P., Keller, M. \& Stetter, K. O. (2008). A korarchaeal genome reveals insights into the evolution of the Archaea. Proc. Natl. Acad. Sci. USA 105, 8102-8107.

28. Waters, E., Hohn, M. J., Ahel, I., Graham, D. E., Adams, M. D., Barnstead, M., Beeson, K. Y., Bibbs, L., Bolanos, R., Keller, M., Kretz, K., Lin, X., Mathur, E., Ni, J., Podar, M., Richardson, T., Sutton, G. G., Simon, M., Soell, D., Stetter, K. O., Short, J. M. \& Noordewier, M. (2003). The genome of Nanoarchaeum equitans: Insights into early archaeal evolution and derived parasitism. Proc. Natl. Acad. Sci. USA 100, 12984-12988.

29. Hallam, S. J., Konstantinidis, K. T., Putnam, N., Schleper, C., Watanabe, Y.-I., Sugahara, J., Preston, C., de la Torre, J., Richardson, P. M. \& DeLong, E. F. (2006). Genomic analysis of the uncultivated marine crenarchaeote Cenarchaeum symbiosum. Proc. Natl. Acad. Sci. USA 103, 18296-18301.

30. Kelman, Z. \& O'Donnell, M. (1995). DNA polymerase III holoenzyme: structure and function of a chromosomal replicating machine. Annu. Revi. Biochem. 64, 171-200.

31. Warbrick, E. (1998). PCNA binding through a conserved motif. Bioessays 20, 195-199.

32. Ducoux, M., Urbach, S., Baldacci, G., Hübscher, U., Koundrioukoff, S., Christensen, J. \& Hughes, P. (2001). Mediation of PCNA-dependent DNA replication through a conserved P21Cip1-like PCNA-binding motif present in the third subunit of human DNA polymerase ઈ. J. Biol. Chem. 276, 49258-49266. 
33. Maga, G., Blanca, G., Shevelev, I., Frouin, I., Ramadan, K., Spadari, S., Villani, G. \& Hübscher, U. (2004). The human DNA polymerase $\lambda$ interacts with PCNA through a domain important for DNA primer binding and the interaction is inhibited by p21/WAF1/CIP1. Faseb J. 18, 1743-5.

34. Pohler, J. R., Otterlei, M. \& Warbrick, E. (2005). An in vivo analysis of the localisation and interactions of human p66 DNA polymerase $\delta$ subunit. BMC Mol. Biol. 6, 17.

35. Shimazaki, N., Yazaki, T., Kubota, T., Sato, A., Nakamura, A., Kurei, S., Toji, S., Tamai, K. \& Koiwai, O. (2005). DNA polymerase lambda directly binds to proliferating cell nuclear antigen through a confined C-terminal region. Genes Cells 10, 705-715.

36. Xu, H., Zhang, P., Liu, L. \& Lee, H. (2001). A novel PCNA-binding motif identified by the fanning of a random peptide display library. Biochemistry USA 40, 4512-4520.

37. Zhang, S. J., Zeng, X. R., Zhang, P., Toomey, N. L., Chuang, R. Y., Chang, L. S. \& Lee, M. Y. W. T. (1995). A conserved region in the amino terminus of DNA polymerase $\delta$ is involved in proliferating cell nuclear antigen binding. J. Biol. Chem. 270, 7988-7992.

38. Mesiet-Cladiere, L., Norais, C., Kuhn, J., Briffotaux, J., Sloostra, J. W., Ferrari, E., Hübscher, U., Flament, D. \& Myllykallio, H. (2007). A novel proteomic approach identifies new interaction partners for proliferating cell nuclear antigen. J. Mol. Biol. 372, 1137-1148.

39. Chapados, B. R., Hosfield, D. J., Han, S., Qiu, J., Yelent, B., Shen, B. \& Tainer, J. A. (2004). Structural basis for FEN-1 substrate specificity and PCNA-mediated activation in DNA replication and repair. Cell 116, 39-50.

40. Gulbis, J. M., Kelman, Z., Hurwitz, J., O'Donnel, M. \& Kuriyan, J. (1996). Structure of the C-terminal region of p21 ${ }^{\text {WAF1/CIP1 }}$ complexed with human PCNA. Cell 87, 297-306. 41. Warbrick, E. (2000). The puzzle of PCNA's many partners. Bioessays 22, 997-1006. 
42. Matsumiya, S., Ishino, Y. \& Morikawa, K. (2001). Crystal structure of an archaeal DNA sliding clamp: Proliferating Cell Nuclear Antigen from Pyrococcus furiosus. Protein Sci. 10, 17-23.

43. Jónsson, Z. O., Hindges, R. \& Hübscher, U. (1998). Regulation of DNA replication and repair proteins through interaction with the front side of proliferating cell nuclear antigen. EMBO J. 17, 2412-2425.

44. Eissenberg, J. C., Ayyagari, R., Gomes, X. V. \& Burgers, P. M. J. (1997). Mutations in yeast proliferating cell nuclear antigen define distinct sites for interaction with DNA polymerase $\delta$ and DNA polymerase $\varepsilon$. Mol. Cell. Biol. 17, 6367-6378.

45. Zhang, P., Sun, Y. B., Hsu, H., Zhang, L. F., Zhang, Y. N. \& Lee, M. Y. W. T. (1998). The interdomain connector loop of human PCNA is involved in a direct interaction with human polymerase $\delta$. J. Biol. Chem. 273, 713-719.

46. Tori, K., Kimizu, M., Ishino, S. \& Ishino, Y. (2007). DNA polymerases BI and D from the hyperthermophilic archaeon Pyrococcus furiosus both bind to proliferating cell nuclear antigen with their C-terminal PIP-box motifs. J. Bacteriol. 189, 5652-5657.

47. Henneke, G., Flament, D., Hübscher, U., Querellou, J. \& Raffin, J. P. (2005). The Hyperthermophilic Euryarchaeota Pyrococcus abyssi likely requires the two DNA polymerases D and B for DNA replication. J. Mol. Biol. 350, 53-64.

48. Jónsson, Z. O. \& Hübscher, U. (1997). Proliferating cell nuclear antigen: more than a clamp for DNA polymerases. Bioessays 19, 967-975.

49. Maga, G. \& Hübscher, U. (2003). Proliferating cell nuclear antigen (PCNA): a dancer with many partners. J. Cell Sci. 116, 3051-3060.

50. Shamoo, Y. \& Steitz, T. A. (1999). Building a replisome from interacting pieces: Sliding clamp complexed to a peptide from DNA polymerase and a polymerase editing complex. Cell 99, 155-166. 
51. Podust, L. M., Podust, V. N., Sogo, J. M. \& Hübscher, U. (1995). Mammalian DNA polymerase auxiliary proteins: Analysis of replication factor C-catalyzed proliferating cell nuclear antigen loading onto circular double-stranded DNA. Mol. Cell Biol. 15, 30723081.

52. Yuzhakov, A., Kelman, Z., Hurwitz, J. \& O'Donnell, M. (1999). Multiple competition reactions for RPA order the assembly of the DNA polymerase $\delta$ holoenzyme. EMBO J. 18, 6189-6199. 


\section{FIGURES}

Figure 1: PIP box motifs in PabPol B and D.

(a) Consensus motifs in PabPol B and D. The PIP box motif localized at level of C-terminal sequence of PabPol B and large subunit of PabPol D. The amino acid residues of PIP box are framed. Arrows show lysine mutated to a stop codon to truncate each protein.

(b) SPR measurements of PabPols and PabPCNA interactions. At time 0, PabPCNA was injected over the immobilized primed ssDNA ${ }^{47}$ as indicated by the black arrow. Then, either PabPol B or PabPol D and their PIP box deleted mutants, respectively PabPol B $\triangle$ pip and PabPol D $\Delta$ pip, were injected as indicated by the grey arrow. The background resulting from the injection buffer alone was subtracted from the data in each case before plotting.

Figure 2: The PIP box of PabPol B, but not of PabPol D, is required for functional interaction with PabPCNA.

Primer extension studies were performed with M13mp18 template (90 fmol), hybridized to a 5'-fluorescein-labeled primer and contained 0.3 pmol of PabPol D, 0.6 pmol of PabPol D $\Delta$ pip, 0.02 pmol of PabPol B $\Delta$ pip or 0.04 pmol of PabPol B. PCNA was added to a ratio 1:1 relative to the DNA polymerase. Primer extension studies were performed as outlined in the materials section. Reactions were incubated at $60^{\circ} \mathrm{C}$ for $30 \mathrm{~min}$, and products were resolved on denaturing alkaline 1\% agarose gels and visualized by Typhoon 9400 imager. Lanes 1 and 2 correspond to controls without the DNA polymerase.

A quantitative analysis was performed by determining the relative amounts of the full-length product by densitometry analysis of the gel. Data are expressed as means \pm SD of the percent full-length product as related to total elongation products. Differences between means were tested by Student's $t$ test for equal variances. Different from control without PCNA: * $\mathrm{P}<$ 
0.01 ; ** $\mathrm{P}<0.005(\mathrm{n}=6)$. Data with PabPol D and PabPol D $\Delta$ pip were not significantly different, in presence or absence of the PCNA, respectively.

Figure 3: Functional interaction of PabPols with PabPCNA in the presence of competitor peptides corresponding to the PIP box motifs.

Primer extension studies were performed with M13mp18 template (90 fmol) hybridized to a 5'-fluorescein-labeled primer. PIPB corresponded to the C-terminal part of PabPol B, PIPD corresponded to the C-terminal part of PabPol D and TEMD was a control peptide corresponding to the amino acids 83-103 of PabPol D. Primer extension studies were performed as outlined in the materials section. Reactions were incubated at $60^{\circ} \mathrm{C}$ for $15 \mathrm{~min}$, and products were resolved on denaturing alkaline $1 \%$ agarose gels and visualized by Typhoon 9400 imager.

(a) PIP box peptides inhibit functional interactions of PabPol B with PabPCNA. The reactions contained $0.04 \mathrm{pmol}$ of PabPol B. PabPCNA was added to a ratio 1:1. Lane 1 corresponds to control without the polymerase. Peptides were added (10 and $30 \mu \mathrm{M})$ at the same time than PabPol B.

(b) PIP box peptides affect functional interactions of PabPol D with PabPCNA. The reactions contained 0.3 pmol of PabPol D and PabPCNA was added at an equimolar ratio. Peptides were added $(30 \mu \mathrm{M})$ at the same time than PabPol D.

(c) PIP box peptides affect functional interactions of PabPol D $\Delta$ pip with PabPCNA. The reactions contained 0.6 pmol of PabPol D $\Delta$ pip and PabPCNA was added at an equimolar ratio. Peptides were added $(30 \mu \mathrm{M})$ at the same time than PabPol D $\Delta$ pip.

Figure 4: Putative PIP box motif localized at N-terminus of large subunit of PabPol D. 
(a) The palindromic PIP box motif localized at level of N-terminal sequence of large subunit of PabPol D. The amino acid residues forming the motif are framed. Arrow show the glutamic acid mutated to a start codon.

(b) The N-terminus of large subunit of PabPol D is not essential for functional interaction with PabPCNA. Primer extension studies were performed with M13mp18 template (90 fmol), hybridized to a 5'-fluorescein-labeled primer and contained 0.3 pmol of PabPol D and 0.7 pmol of PabPol DNcut. PCNA was added to ratios 1:3, 1:1 and 3:1 relative to DNA polymerase (symbolized by a triangle). Primer extension studies were made as outlined in the materials section. Reactions were incubated at $60^{\circ} \mathrm{C}$ for $30 \mathrm{~min}$, and products were resolved on denaturing alkaline 1\% agarose gels and visualized by Typhoon 9400 imager. Lanes 1 corresponds to control without the DNA polymerase.

A quantitative analysis was performed by determining the relative amounts of the full-length product by densitometry analysis of the gel. Data are expressed as means \pm SD of the percent full-length product as related to total elongation products. Differences between means were tested by Student's $t$ test for equal variances. Different from control without PCNA: ** P < 0.005 ( $\mathrm{n}=3)$. Data with PabPol D and PabPol D $\Delta$ pip were significantly different when the PCNA was present $(\mathrm{P}<0.005)$.

Figure 5: Functional interaction of PabPol D with PabPCNA in the presence of competitor peptides mimicking to the N-terminus of PabPol D.

Primer extension studies were performed with M13mp18 template (90 fmol) hybridized to a 5'-fluorescein-labeled primer. Nter 1 and Nter 2 corresponded to the N-terminal part of large subunit of PabPol D, respectively the amino acids 1-15 and 15-29 (see Materials and Methods). TEMD was a control peptide corresponding to the amino acids 83-103 of PabPol D. The reactions contained 0.3 pmol of PabPol D. PabPCNA was added to an equimolar 
ratio. Increasing amounts of peptides were added (50 $\mu \mathrm{M}, 100 \mu \mathrm{M}, 500 \mu \mathrm{M}$ and $1000 \mu \mathrm{M})$ at the same time than PabPol D, excepted for lanes 4 to 7 where the amount of TEMD were doubled, i.e. $100 \mu \mathrm{M}, 200 \mu \mathrm{M}, 1000 \mu \mathrm{M}$ and $2000 \mu \mathrm{M}$. Primer extension studies were made as outlined in the materials section. Reactions were incubated at $60^{\circ} \mathrm{C}$ for $15 \mathrm{~min}$, and products were resolved on denaturing alkaline 1\% agarose gels and visualized by Typhoon 9400 imager. Lane 1 corresponds to control without the DNA polymerase.

Figure 6: Mutations effected on IDCL and C-terminus of PabPCNA corresponding to the hydrophobic pocket.

On the right, the 3D structure of a PCNA monomer with the mutated amino acids.

Figure 7: Functional interaction of PabPol B and PabPol D, PabPol D $\Delta$ pip and PabPol DNcut with PabPCNA mutated in the hydrophobic pocket. Primer extension studies were performed with M13mp18 template (90 fmol) hybridized to a 5'-fluorescein-labeled primer. Primer extension studies were made as outlined in the materials section. Products were resolved on denaturing alkaline 1\% agarose gels and visualized by Typhoon 9400 imager. The reactions contained (a) 0.04 pmol of PabPol B. Wild type and mutants PCNA were added at an equimolar ratio, as related to the Pol; (b) 0.3 pmol of PabPol D; (c) 0.6 pmol of PabPol D $\Delta$ pip; (d) 0.7 pmol of PabPol DNcut.

PCNA : Pol ratio was 3:1. 
a)

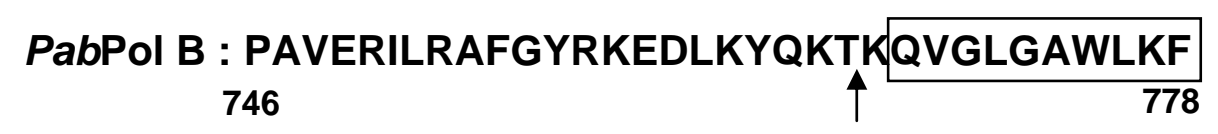

PabPol D : TEKAEKAEKPRKKSDEKPKKKRVISLEEFFSRKSK 1421

1455

b)

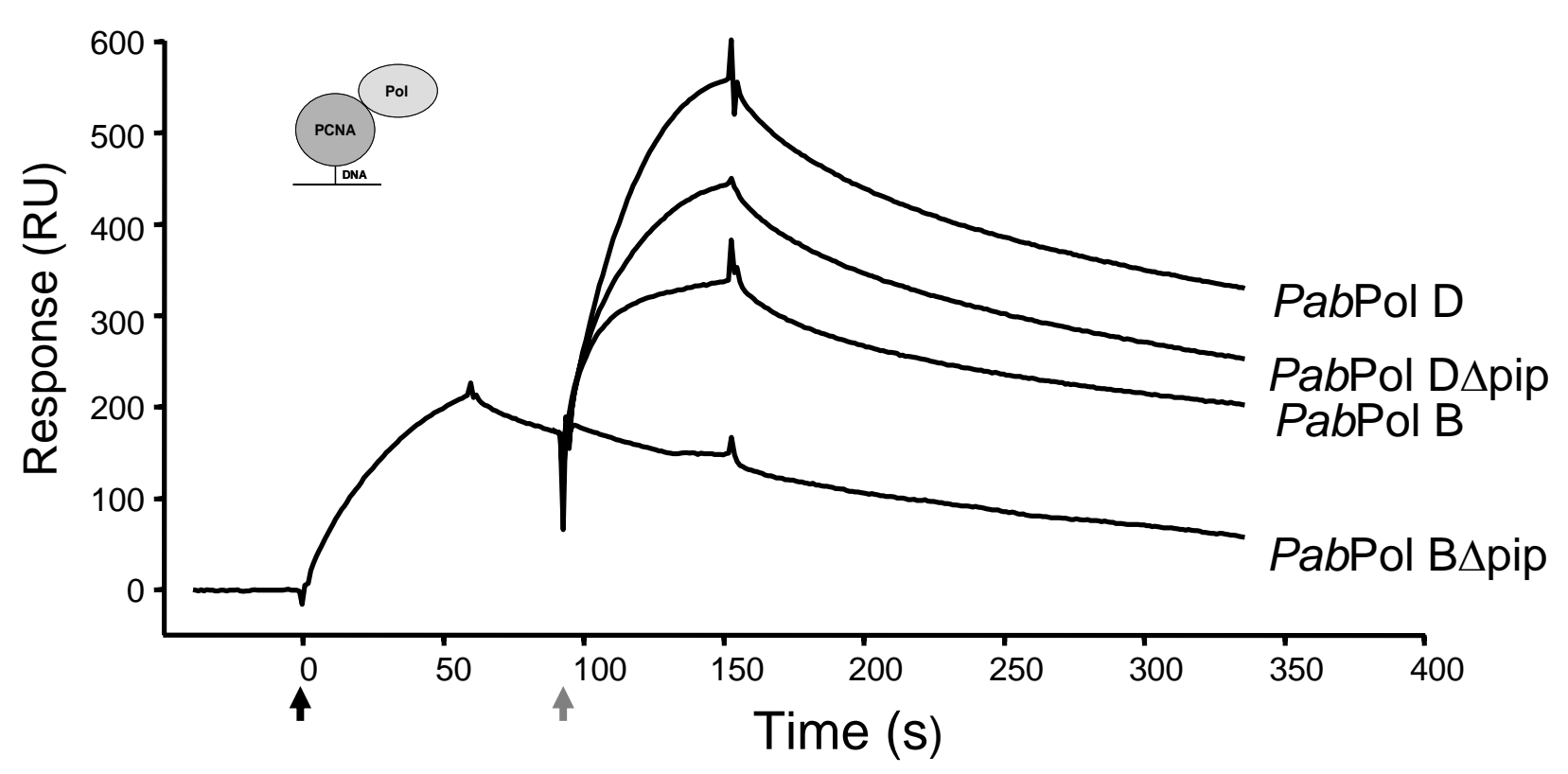


Fig 2

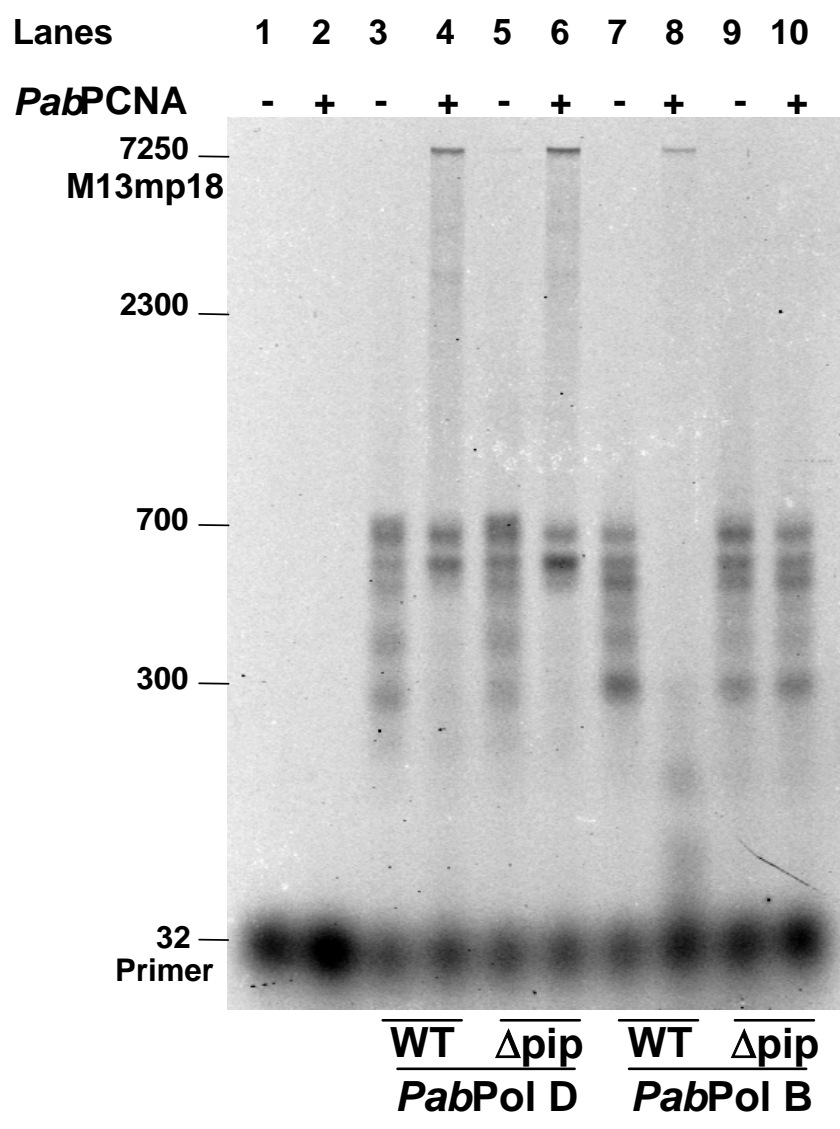

\begin{tabular}{ccc}
\hline & PabPol D & PabPol D $\Delta$ pip \\
\hline - PCNA & $0.4 \pm 0.8$ & $1.1 \pm 0.8$ \\
+ PCNA & $6.7 \pm 3.8^{\star \star}$ & $5.0 \pm 2.6^{\star}$ \\
\hline
\end{tabular}




\section{Fig 3}

a)

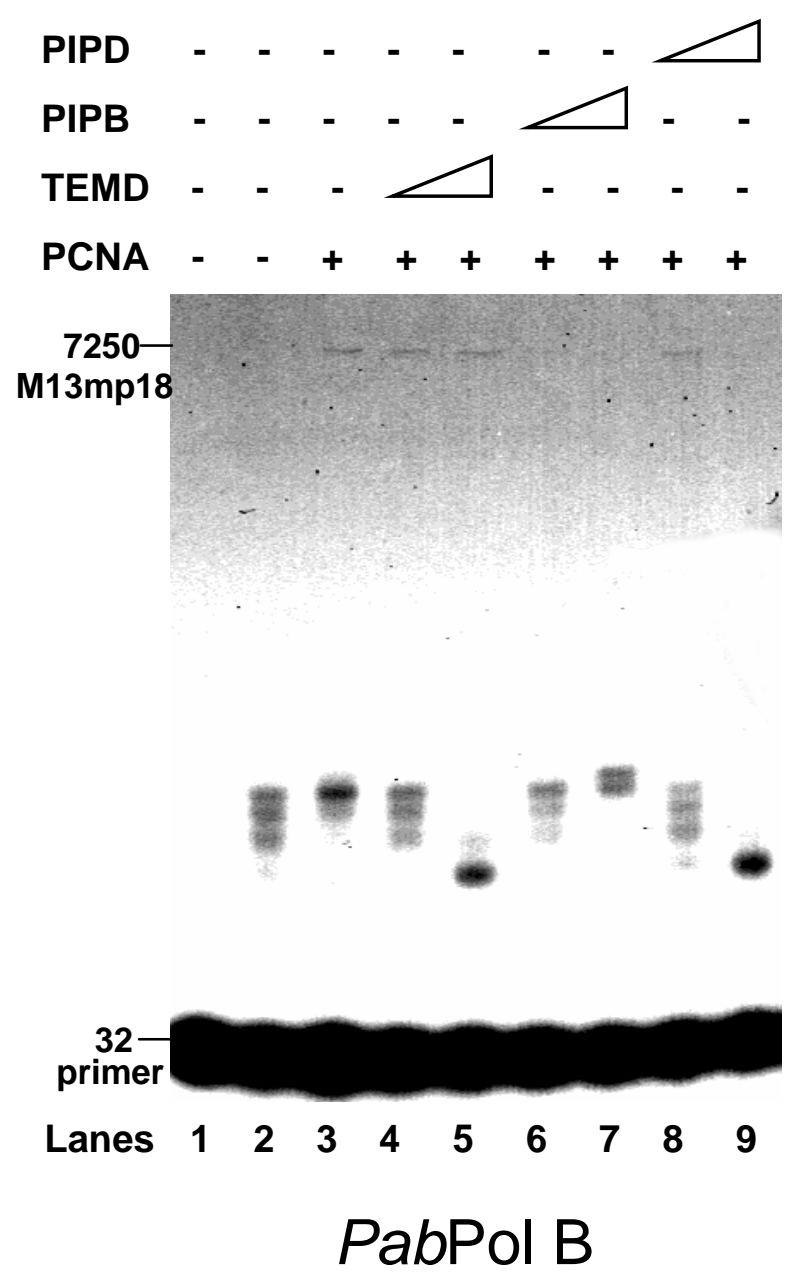

b)

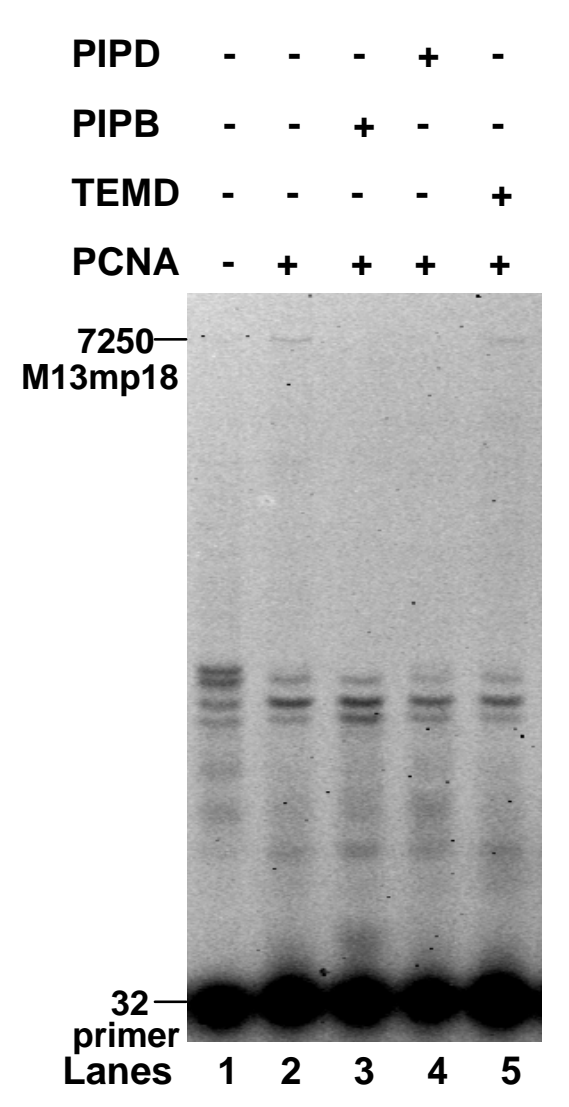

PabPol D c)

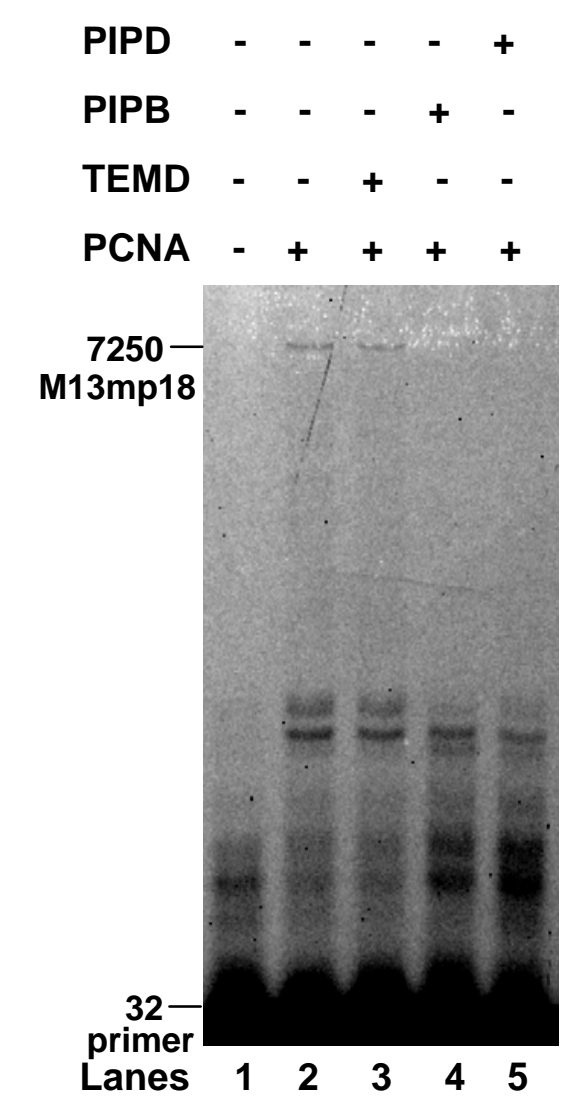

PabPol D $\Delta$ pip 
Fig 4

a) MELPKEMEEYEEMLQREIDKAYEIAKKAR

b)

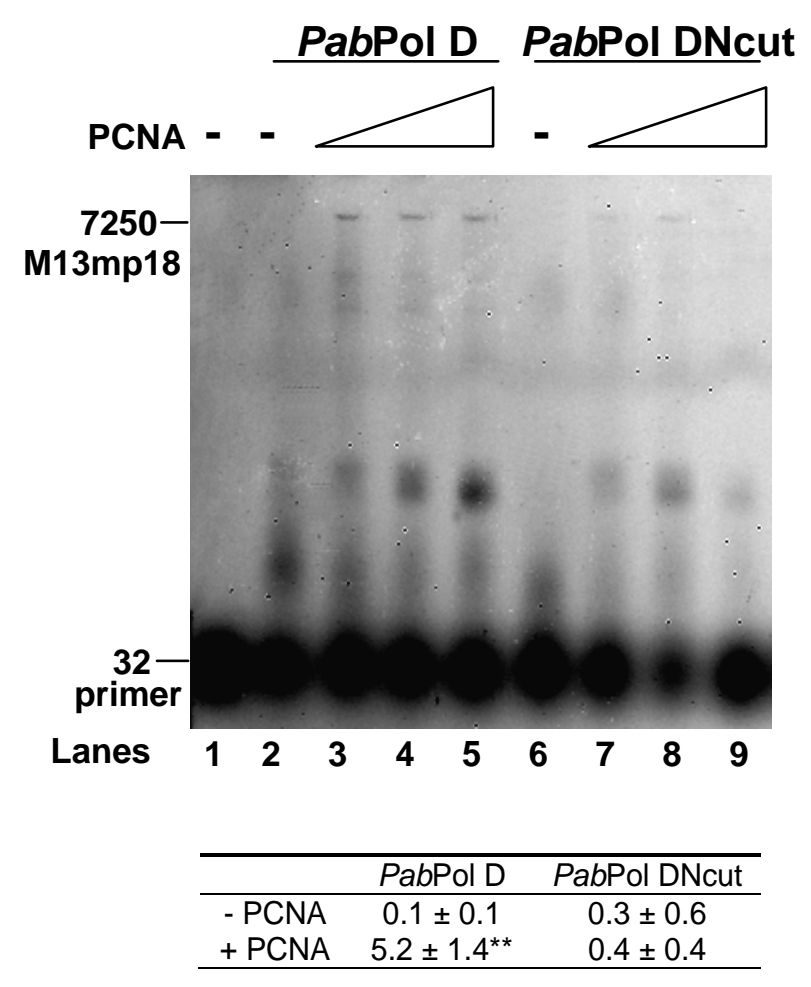




\section{Fig 5}

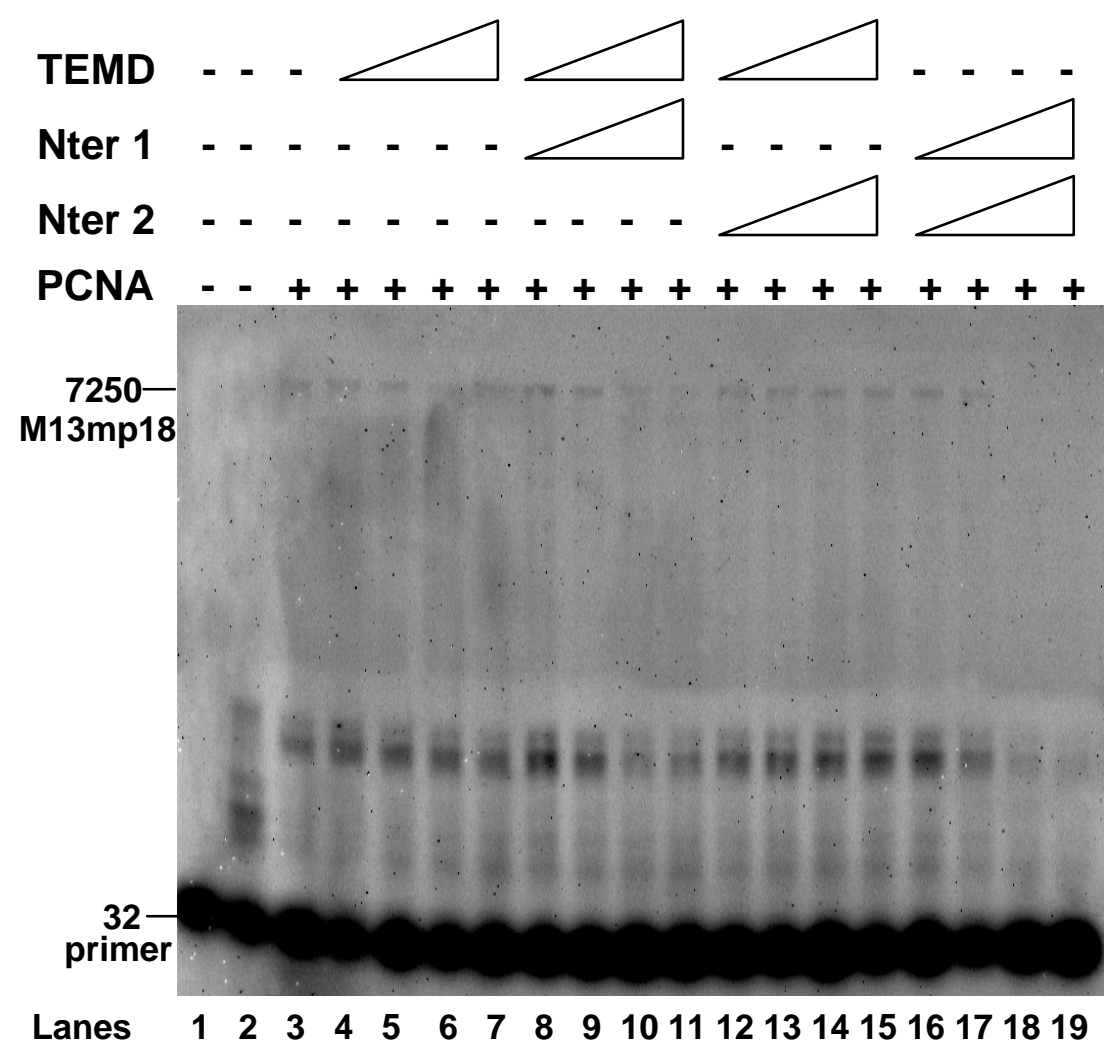




\section{Fig 6}

\begin{tabular}{ll}
\hline Proteins & Mutations on IDCL \\
\hline PCNA & ${ }_{115}$ LIDVEEIEVDLPELPFT $_{131}$ \\
EIE120 & ${ }_{115}$ LIDVEAAAVDLPELPFT $_{131}$ \\
VDL123 & ${ }_{115}$ LIDVEEIEAAAPELPFT $_{131}$ \\
EL127 & ${ }_{115}$ LIDVEEIEVDLPAAPFT $_{131}$ \\
\hline Proteins & Mutations on C-terminus $^{2}$ \\
\hline PCNA & ${ }_{243}$ LAPRVEE $_{249}$ \\
PR245 & ${ }_{243}$ LAAAVEE $_{249}$ \\
\hline
\end{tabular}

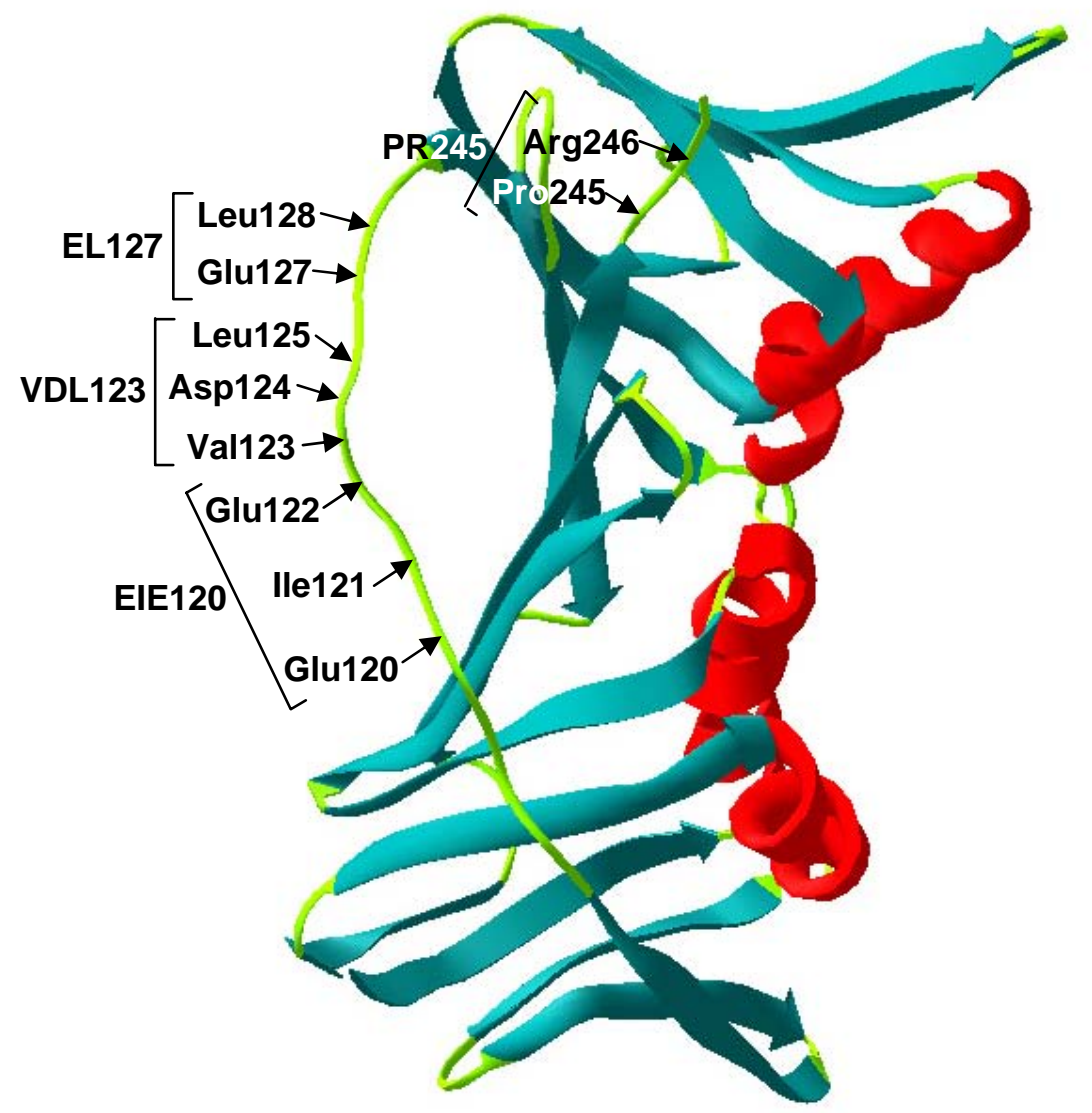




\section{Fig 7}

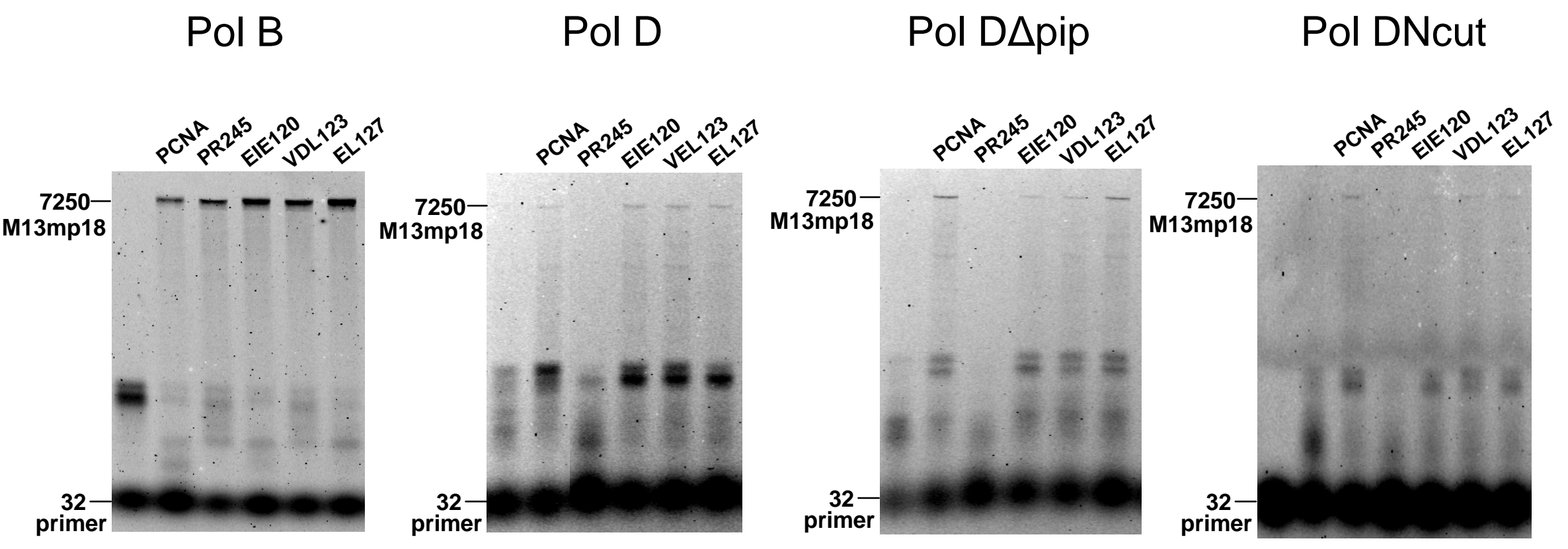

